\title{
Synthesis of a Potentially Bioactive, Hydroxyapatite-Nucleating Molecule
}

\author{
S. Chang, ${ }^{1}$ H. Chen, ${ }^{1}$ J. Liu, ${ }^{1}$ D. Wood, ${ }^{2}$ P. Bentley, ${ }^{2}$ B. Clarkson ${ }^{1}$ \\ ${ }^{1}$ Department of Cariology, Restorative Sciences, and Endodontics, University of Michigan, Ann Arbor, MI, USA \\ ${ }^{2}$ Division of Restorative Dentistry, University of Leeds, Leeds, United Kingdom
}

Received: 11 August 2005 / Accepted: 22 August 2005 / Online publication: 6 January 2006

\begin{abstract}
A human phosphophoryn (PP) cDNA was previously cloned from immature root apex total RNA in our laboratory. This cDNA comprises $2,364 \mathrm{bp}$, encoding 788 amino acids. More than $80 \%$ of the sequences are arranged as (DSS $)_{n}(n=1-16)$, DS, and NSS motifs. We hypothesize that the capability of PP to bind $\mathrm{Ca}^{2+}$ and nucleate hydroxyapatite may depend on these repeated sequences. Two polypeptides were synthesized based on the human PP cDNA sequence to test the hypothesis. One polypeptide has the amino acid sequence DDPNSSDESNGNDD (synthetic polypeptide 1 , SP1), which is from the N-terminal end of PP; the other polypeptide, DSKSDSSKSESDSS (synthetic polypeptide 2, SP2), is the PP repeated sequence motif. Phosphorylation of the polypeptides was accomplished by reacting them with adenosine triphosphate and casein kinases I and II. The ability of these molecules to cause mineralization was tested in a steady-state agarose gel system. The results show that phosphorylated SP2 (PSP2) precipitated approximately $60 \%$ of the total $\mathrm{Ca}+$ $\mathrm{PO}_{4}$ precipitated by PP. P-SP1 precipitated about $23 \%$ of that precipitated by PP and was similar to the amount precipitated in the control gel, that is, without added peptides. Transmission electron microscopy and X-ray diffraction analysis showed that the precipitate formed in the P-SP2-containing gel was hydroxyapatite. The capability of P-SP2 to nucleate $\mathrm{Ca}+\mathrm{PO}_{4}$ and precipitate hydroxyapatite is a result of the repeated sequence motif, which contains a high percentage of phosphorylated serine. This molecule could be used in the repair and regeneration of dental tissue.
\end{abstract}

Key words: Human — Phosphophoryn - Polypeptide - Hydroxyapatite - Nucleation

The dentin mineralization process involves the formation and growth of hydroxyapatite (HA) crystals in an extracellular matrix. Type I collagen accounts for $90 \%$ of the extracellular matrix of dentin. The collagen fibers provide the framework for HA deposition and the subsequent crystal growth to form a mineralized matrix. This biomineralization process is highly regulated by a set of matrix proteins which are secreted by odontoblasts. The function of these dentin matrix proteins in

Correspondence to: S. Chang; E-mail: renchang@umich.edu dentin mineralization has been widely discussed [1-3]. Of these dentin matrix proteins, phosphophoryn (PP) is the most abundant noncollagenous protein. More than $80 \%$ of this protein's amino acid composition is aspartic acid and serine, and $85-90 \%$ of the serine residues are phosphorylated [4-6]. These unique characteristics make PP a very acidic protein. Early studies have suggested that PP is a mineral nucleator [7, 8] and may have the ability to regulate $\mathrm{HA}$ formation $[9,10]$. Later studies have shown that PP affects in vitro mineralization in various ways. Linde and Lussi [11] reported that mineral formation could be induced at low supersaturation by covalently binding rat $\mathrm{PP}$ to agarose beads and, conversely, that mineral formation could be inhibited when PP was free in the solution. The concentration of PP has also been shown to affect HA formation and growth in a gelatin gel system: low concentrations $(0.01-1 \mu \mathrm{g} / \mathrm{mL})$ promoted HA formation and higher concentrations $(100 \mu \mathrm{g} / \mathrm{mL})$ inhibited HA growth [12, 13]. Another important acidic extracellular matrix protein, dentin matrix protein 1 (DMP-1), was shown to be expressed in the early stages of dentin mineralization, and the expression decreased after the appearance of mineral formation [14]. Thus, it is postulated that DMP-1 has a regulatory role in dentin mineralization. The amino acid composition of DMP-1 contains $28 \%$ glutamic acid and aspartic acid, which suggests that DMP-1 should have a great capacity to bind divalent cations such as calcium [15]. In an in vitro Ca binding assay and nucleating test, recombinant DMP-1 showed not only strong $\mathrm{Ca}$ binding ability but also the capability of assembling $\mathrm{Ca}$ and phosphate ions to facilitate HA crystal formation [16, 17]. A recent in vitro study of apatite growth in a gelatin gel system showed that the length and degree of phosphorylation of DMP-1 affected the initiation and regulation of mineral formation. DMP-1 initiates mineralization when it is dephosphorylated or cleaved but inhibits mineralization when it is in its native form [18].

Phosphorylation of acidic dentin matrix proteins such as DMP-1 and PP has been reported to affect crystal nucleation and subsequent mineral formation $[8$, 


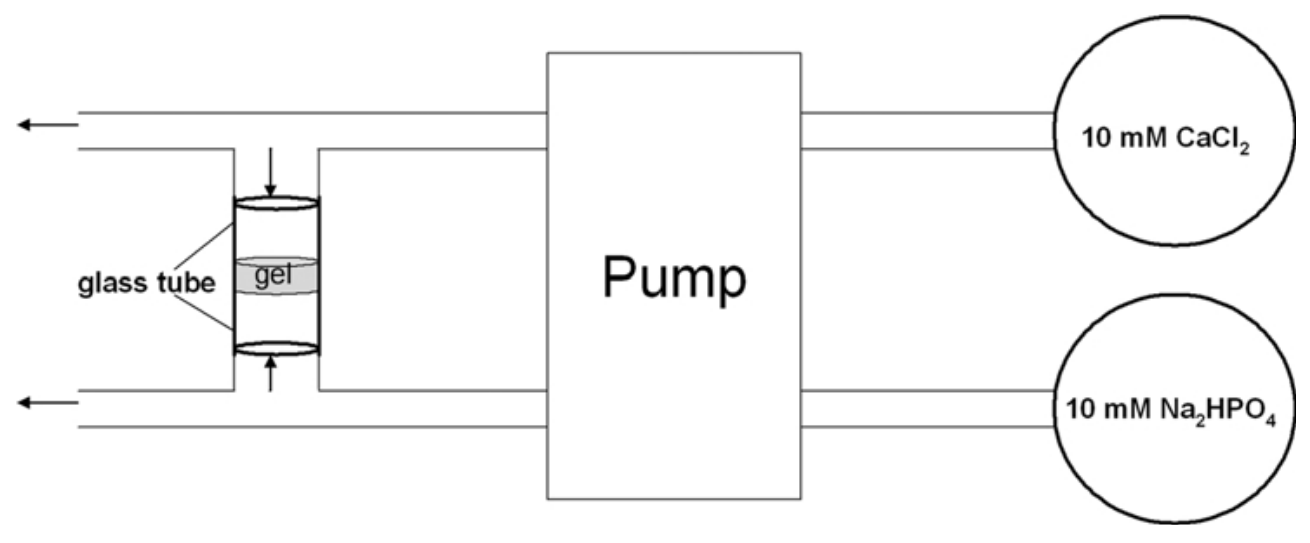

Fig. 1. Schematic illustration of the steady-state agarose gel system. From two separate reservoirs containing $10 \mathrm{mM} \mathrm{CaCl}_{2}$ and $\mathrm{Na}_{2} \mathrm{HPO}_{4}$, the solutions were pumped independently and flowed continuously at approximately $1 \mathrm{~mL} / \mathrm{hr}$ through the apparatus. The system is not drawn to scale.
18-20]. More direct evidence using atomic force microscopy revealed that PP had a stronger binding capacity to enamel crystals than dephosphorylated PP [21]. Casein kinase I (CK1) and CK2 have been reported to be involved in the phosphorylation of PP [22-24]. The unique characteristic property of the (DSS $)_{n},(\mathrm{DS})_{n}$, and $(\mathrm{NSS})_{n}(\mathrm{n} \gg 10)$ repeated motifs of PP have made it an ideal substrate for CK1 and CK2 kinase activity. These repeated motifs constitute $>80 \%$ of the PP amino acid sequence and are essential for its phosphorylation, $\mathrm{Ca}$ interaction, and subsequent effects on dentin mineralization $[25,26]$. Two acidic phosphorylated, serinerich proteins, DMP-2 and DMP-3, also have the repeated triplet DSS motif, with DMP-2 having many more repeated DSS than DMP-3 [25, 27]. DMP-2 and DMP-3 have been reported to be related to dentinogenesis imperfecta II [28].

DSP is another extracellular matrix protein that has been widely investigated. DSP and PP are the cleavage products from a large transcript encoded by the gene dentin sialophosphoprotein (DSPP) [29-31], but the amount of DSP found in dentin is much less than that in DPP. The DSP transcript is expressed in odontoblasts and transiently expressed in preameloblasts [32]. Immunohistochemical studies of DSP have shown that it is present in dentin and predentin [33-35]. These results indicate a role for DSP in dentin mineralization, but as yet this role has not been defined. A gelatin gel diffusion study has shown that DSP had only a limited effect on HA formation and growth [36], which may be because it has a low affinity for HA crystals [21].

The goal of this study was to explore whether the phosphorylated repeated motifs of PP, which consist of DSS, DS, and NSS, determine the ability of PP to nucleate HA and whether this ability could be replicated by a synthesized molecule. Different molecules were used in this experiment, including synthetic polypeptide 1 (SP1) from the N-terminal end of PP, SP2 from the repeated sequence of $\mathrm{PP}$, human $\mathrm{PP}$, and human DSP. SP1 and SP2 were phosphorylated by reacting them with adenosine triphosphate (ATP) and CK1/CK2 or used as unphosphorylated molecules. The ability of all these molecules to nucleate mineral was tested in a $\mathrm{Ca}$ and phosphate buffer steady-state gel system. The apatitic nature of the precipitate was determined by X-diffraction and energy-dispersive X-ray analysis (EDAX).

\section{Materials and Methods}

The steady-state agarose gel system consisted of two reservoirs, one filled with $10 \mathrm{mM} \mathrm{CaCl}$ and the other with $10 \mathrm{mM}$ $\mathrm{Na}_{2} \mathrm{HPO}_{4}$. Both solutions contained $150 \mathrm{mM} \mathrm{NaCl}, 0.01 \%$ $\mathrm{NaN}_{3}$, and $10 \mathrm{mM}$ Tris- $\mathrm{HCl}(\mathrm{pH} 7.4)$ and were connected through glass tubes in which $10 \mu \mathrm{g}$ of the test molecules were mixed with agarose gel at a final concentration of $2 \%$ (Fig. 1). The test molecules were prepared as follows.

$P P$. Open root apices from freshly extracted human immature third molar teeth were obtained and demineralized in $10 \%$ ethylenediaminetetraacetic acid (EDTA) plus protease inhibitors. After 1 week of extraction, the EDTA soluble fraction was collected and dialyzed against distilled water. Calcium chloride (1 M) was added to precipitate PP, the precipitation was redissolved in EDTA and run on a $7.5 \%$ polyacrylamide gel, and the PP band (140 kDa) was dissected from the gel. The band was eluted using an electroeluter (Bio-Rad, Richmond, CA) and desalted in a Microcon column (Millipore, Bedford, MA).

$D S P$. The protein was purified from human immature tooth dentin using Butler's three-step method [37]. The dentin was demineralized in $0.25 \mathrm{M}$ EDTA plus $4 \mathrm{M}$ guanidum- $\mathrm{HCl}$ $(\mathrm{GdmCl})$ and protease inhibitors for 2 weeks. The EDTA/ $\mathrm{GdmCl}$ extract was desalted and precipitated with $1 \mathrm{M} \mathrm{CaCl}_{2}$ to remove DPP. The supernatant was dialyzed against $0.1 \mathrm{M}$ formic acid to recover the acid soluble fraction. The acid soluble fraction was separated using a Sephadex G-50 (Sigma, St. Louis, MO, USA) column. This DSP-containing fraction was further purified in a Bio-Gel P-2 column (Bio-Rad, Richmond, CA, USA).

Both PP and DSP prepared by the methods described above resolved as a single band on sodium dodecyl sulfatepolyacrylamide gel electrophoresis gels.

SP1: DDPNSSDESNGNDD. SP1 was synthesized based on the human PP N-terminal sequence (Invitrogen, Carlsbad, CA).

SP2: DSKSDSSKSESDSS. SP2 was synthesized based on the human PP repeated sequence motifs (Invitrogen). 
$P-S P 1$ and $P-S P 2$. The SP1 and SP2 sequences were phosphorylated using a CK1 and CK2 phosphorylation kit (Upstate Biotechnology, Lake Placid, NY). The final concentration of $1 \mu \mathrm{g} / \mu \mathrm{L}$ was obtained by dissolving the polypeptide in assay dilution buffer. Ten microliters of the polypeptide solution were added to the microcentrifuge tube and mixed with $10 \mu \mathrm{L}$ of CK1 (100 ng) plus $10 \mu \mathrm{L}$ of $0.5 \mathrm{mM}$ ATP. The mixture was incubated in a shaking water bath at $30^{\circ} \mathrm{C}$ for $10 \mathrm{~min}$ and boiled to arrest CK1 activity. Ten microliters of CK2 (100 ng) were then added to the mixture, which was incubated under the same conditions for $10 \mathrm{~min}$ and again boiled to stop the enzyme activity.

The control group in this experiment had the same concentration of agarose gel but no added peptide.

\section{Experimental Procedure}

The $\mathrm{Ca}$ and $\mathrm{PO}_{4}$ solutions ( $\mathrm{pH}$ 7.4) were pumped at a flow rate of $1 \mathrm{~mL} /$ hour through an apparatus which allowed $\mathrm{Ca}$ and phosphate to diffuse separately into the agarose gel from opposite sides. After 6 days at $37^{\circ} \mathrm{C}$, gels were removed from the tubes and rinsed with distilled water before being analyzed for $\mathrm{Ca}$ and $\mathrm{PO}_{4}$. The apatitic nature of the precipitate was also determined.

\section{$\mathrm{Ca}$ and $\mathrm{PO}_{4}$ Analysis}

The precipitate formed a band in the gel, which was dissected from the gel and heated in a microwave. Ten microliters of the liquid gel were immediately added to $1 \mathrm{~mL}$ of reaction solution from a quantitative, colorimetric Ca determination kit (Sigma, St. Louis, MO). The reaction mixture was incubated at $37^{\circ} \mathrm{C}$ until the purple color developed. The intensity of the color was measured spectrophotometerically at $575 \mathrm{~nm}$, and the amount of $\mathrm{Ca}$ was determined by comparing the absorbance to a $\mathrm{Ca}$ standard curve.

For $\mathrm{PO}_{4}$ analysis, the precipitating bands in the gels were dissected, heated to dryness at $200^{\circ} \mathrm{C}$, and dissolved in $1.5 \mathrm{~mL}$ of nitric acid. Samples were heated at $225^{\circ} \mathrm{C}$ until the volume was reduced to $0.1 \mathrm{~mL}$ before a molybdate-ascorbic acid solution was added. Phosphorus was determined by measuring the intensity of the color reaction using the method described by Chen et al. [38].

A center section, at the approximate interface of the diffusing $\mathrm{Ca}$ and $\mathrm{PO}_{4}$ ions, was dissected from the gels that did not contain the precipitate and subjected to analysis as described above.

\section{Crystal Analysis}

The precipitate was dissected from the gel and heated by microwave as previously described. After the precipitate was suspended in methanol, $2 \mu \mathrm{L}$ of it was pipetted onto transmission electron microscope (TEM) copper grids. TEM images were obtained using a JEOL 2010F analytical electron microscope (JEOL, Peabody, MA). The accelerating voltage was $200 \mathrm{kV}$ and the vacuum of the system was $10^{-7}$ torr. The $\mathrm{Ca} / \mathrm{P}$ ratio was based on electron dispersive spectroscopy (EDS) measurements using an EDAX r-TEM detector with EDAX acquisition software (EDAX, Mahwah, NJ, USA). Commercially available HA (Sigma) was used as a standard for the EDAX determination.

The apatitic nature of the precipitate was determined using an X-1 powder diffractometer (Scintag, Cupertono, CA). The diffraction patterns were compared to the instrument's standard HA pattern. To obtain accurate lattice parameters, a Rietveld refinement of the pattern produced by the P-SP2 precipitate was carried out based on high-resolution powder diffraction data [39] for pure HA.

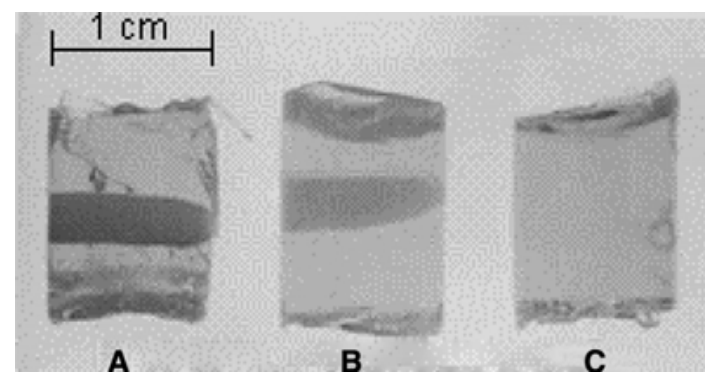

Fig. 2. Cross section of the gels which were removed from the glass tubes after 6 days of incubation. Liesgang rings were observed when PP (A) or P-SP2 (B) was added to the gel. The control gel with no peptides added showed no precipitation $(\mathbf{C})$.

\section{Results}

In Figure 2, after 6 days of incubation in the steadystate gel system, the agarose gel containing PP (A) and P-SP2 (B) showed distinct precipitating bands: Liesgang rings. The Liesgang ring formed presumably at the interface of the $\mathrm{Ca}$ and $\mathrm{PO}_{4}$ ions as they diffused through the gel. No such Liesgang ring was seen in the control group (C), which indicated that spontaneous precipitation did not occur in our steady-state gel system. The bands in the PP gel were more distinct than the one that contained P-SP2. Neither Liesgang ring formation nor obvious precipitation was seen in the DSP-, SP1-, SP2-, and P- SP1-containing gels.

Figure 3 shows the total amount of $\mathrm{Ca}+\mathrm{PO}_{4}$ in the gels with and without added peptides. The gel containing PP had the greatest amount of $\mathrm{Ca}+\mathrm{PO}_{4}$ at $55 \mu \mathrm{g}$, and the control gel had approximately $13 \mu \mathrm{g}$. The DSPcontaining gel had $22 \mu \mathrm{g}$, which is $40 \%$ of that seen for the PP-containing gel and $169 \%$ of that for the control gel. The SP1-containing gel had approximately $18 \mu \mathrm{g}$ of total $\mathrm{Ca}+\mathrm{PO}_{4}$, which is $32 \%$ and $138 \%$ compared to the PP-containing gel and control gel, respectively. The gels containing SP2 and P-SP1 had similar amounts of total $\mathrm{Ca}+\mathrm{PO}_{4}$ to that of the control gel and are approximately $23 \%$ of that seen in the PP-containing gel. The P-SP2-containing gel had approximately $33 \mu \mathrm{g}$, or $60 \%$ of the total $\mathrm{Ca}+\mathrm{PO}_{4}$ precipitated in the PPcontaining gel and $253 \%$ of that in the control gel.

The TEM image of the precipitate from the P-SP2containing gel is shown in Figure 4. The image shows small hexagonal crystals (see arrows), which resemble those of enamel HA. The $\mathrm{Ca} / \mathrm{PO}_{4}$ ratio was $1.58: 1.62$ when analyzed by EDS.

Figure 5 shows the $\mathrm{X}$-ray diffraction result of the precipitates formed by PP (A) and P-SP2 (B) in the agarose gels. These $\mathrm{X}$-ray diffraction patterns (A and $\mathrm{B}$ ) were the same as that for the standard HA pattern (C). All had a major peak at $2.8 \mathrm{~d} \AA$ and a minor one at 3.4 $\mathrm{d} \AA$ (interplanar space). We concluded that the precipitates formed by P-SP2 and PP were HA. The Rietveld refinement showed that the lattice parameters of the HA 


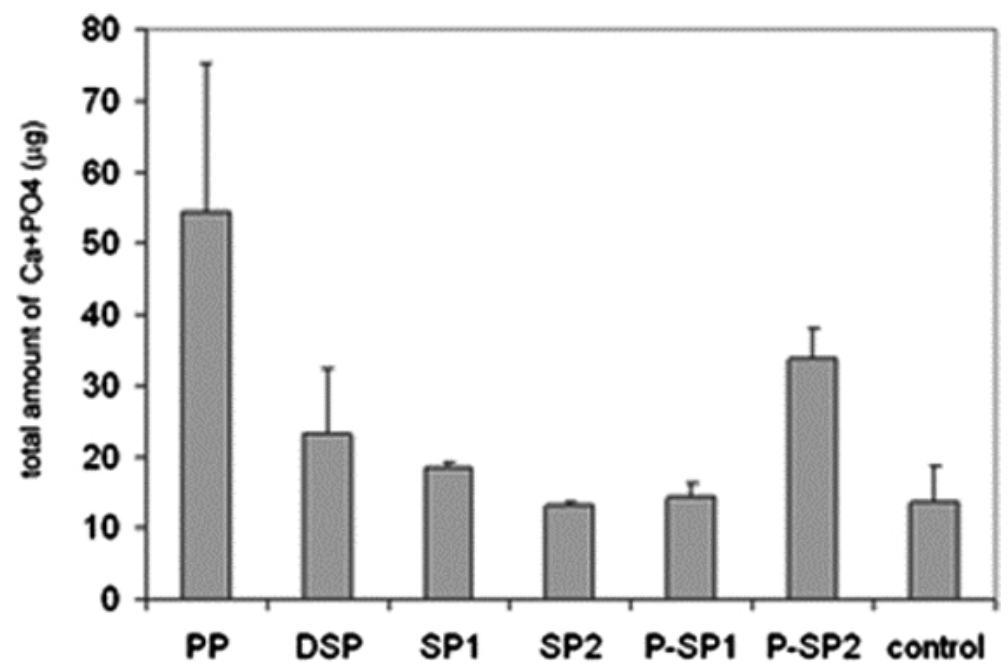

Fig. 3. Total precipitated amount of $\mathrm{Ca}+\mathrm{PO}_{4}$ in the gels containing different molecules. The control gel contained no peptides. The standard deviations shown are based on $n=5$.

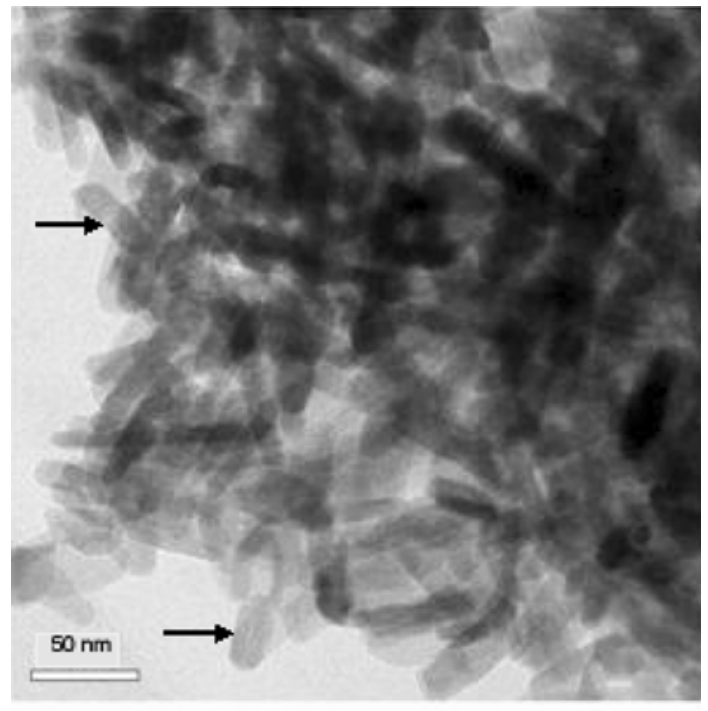

$\mathrm{Ca} / \mathrm{P}=1.58-1.62$

Fig. 4. TEM image of the precipitate in the P-SP2-containing gel, with arrows showing the individual HA crystals.

precipitate formed by P-SP2 were a $=9.392 \AA$, $\mathrm{b}=9.392 \AA, \mathrm{c}=6.851 \AA$.

\section{Discussion}

The technique of using part of the sequences from a whole protein to investigate the function of a polypeptide has been reported by several laboratories. Fujisawa et al. [40] synthesized a polyglutamic acid sequence which could be bound to HA, proving that the binding of osteonectin to HA was due to a region which contained glutamic acid-rich sequences. Tye et al. [41] used recombinant rat bone sialoprotein (rBSP) to investigate the role of two polyglutamic acid (poly [E]) regions involved in HA nucleation. Site-directed mutagenesis of the poly [E] domains was performed, and the HA- nucleating ability was evaluated and compared to unmodified rBSP in a steady-state agarose gel system similar to ours. They successfully demonstrated that the second poly [E] domain of BSP was the one responsible for HA nucleation. To investigate PP's HA-nucleating ability, we synthesized two polypeptides based on the human PP sequence: one from the $\mathrm{N}$ terminus of PP which did not contain serine-rich sequences (SP1) and the other from the repeated motifs of PP which did contain the serine-rich sequences (SP2). The SP1 and SP2 effect on HA nucleation was similar to that of the control group even though SP2 had about $60 \%$ of its amino acids as serine residues. P-SP1, like SP1, had little or no effect on HA nucleation. However, P-SP2 promoted HA nucleation and formation. It was deduced that the percentage of serine residues in the molecule was not the factor affecting HA formation but rather their phosphorylation. Our results show that PP is very capable of HA nucleation in this system. P-SP2 also had this capability but not to the same extent as PP. The difference in their nucleating capabilities is probably due to the degree of phosphorylation, which is affected by the length of repeated motifs and their conformation arrangement. The phosphorylation of $\mathrm{PP}$ by $\mathrm{CK} 1 / 2$ is hierarchical. The initial phosphorylation of several of the serine residues quickly results in the remaining serines within the triple sets becoming substrate for the $\mathrm{CK}$ reaction [24]. The serines which were phosphorylated in SP2 based on the possible CK1 and CK2 phosphorylation sites are as follow: D-S $-K-S^{1}-D-S^{2 *}$ $\mathrm{S}^{1^{*}, 2}-\mathrm{K}-\mathrm{S}^{2}-\mathrm{E}-\mathrm{S}-\mathrm{D}-\mathrm{S}^{1}-\mathrm{S}$ (1 denotes the CK1 primary phosphorylation site and $1 *$, the secondary phosphorylation site; 2 denotes the CK2 primary phosphorylation site and $2^{*}$, the secondary phosphorylation site). P-SP2 was analyzed using mass spectrometry to determine how many serines were actually phosphorylated. Our result showed that there were five serines phosphorylated in the P-SP2 molecule, which was less than expected. The 

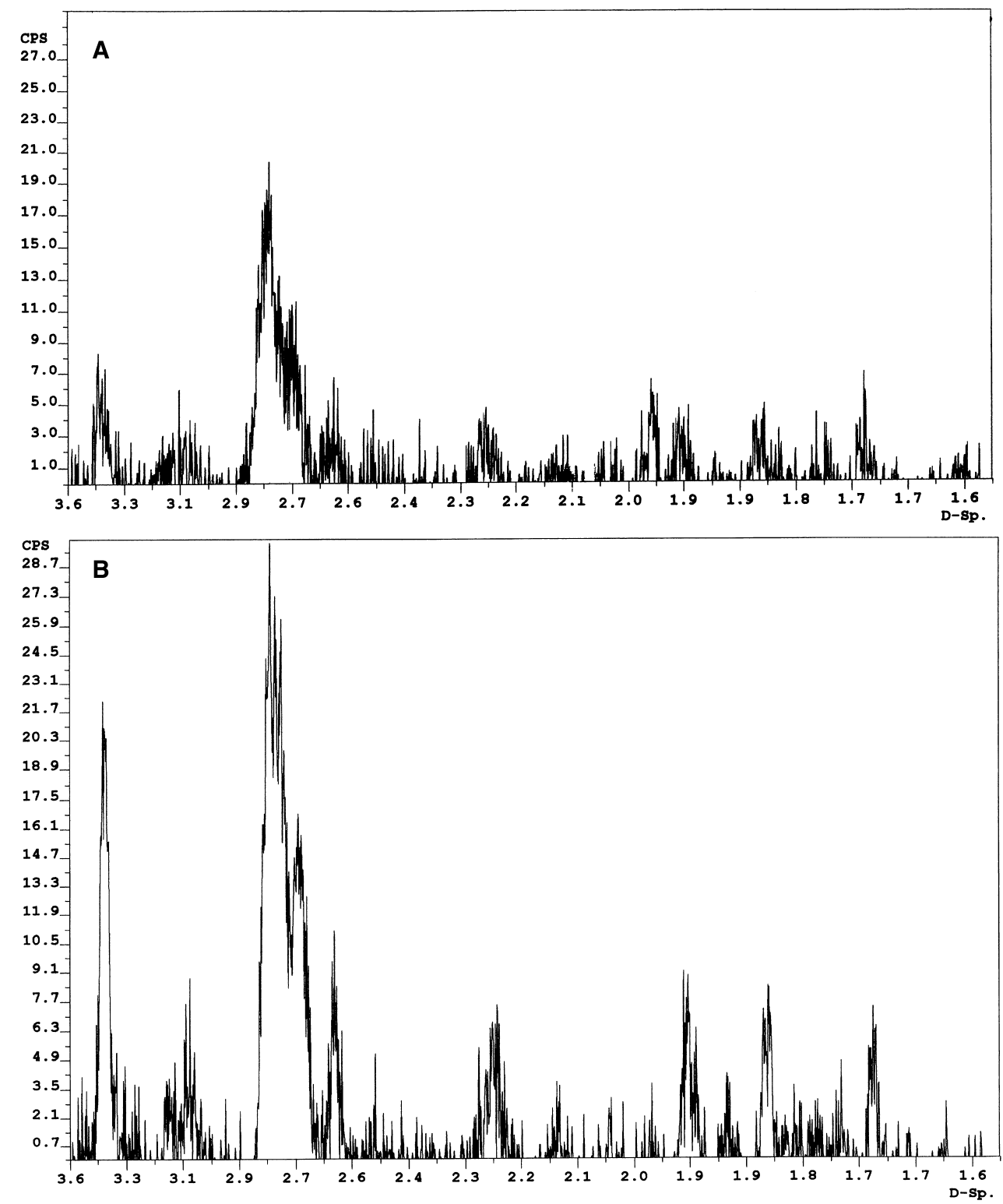

Fig. 5. XRD analysis of the precipitate formed in PPcontaining gel $(\mathbf{A})$ and in P-SP2-containing gel

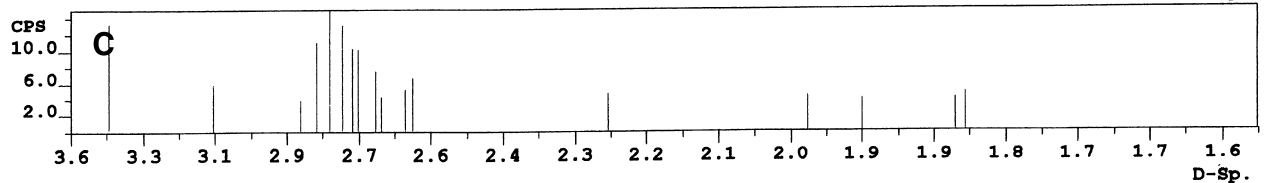

(B). Vertical lines show the diffraction profile of the HA standard used in the Scintag diffractometer $(\mathbf{C})$.

reason for this is unclear. The short SP2 sequence may affect the phosphorylation of the CK1 and CK2 phosphorylation sites. Extending SP-2 would obviously increase the number of serine phosphorylation sites, thus resulting in a greater degree of nucleation.

Another possible factor that would affect biomineralization is conformational arrangement of the repeated motif. George et al. [26] used energy-minimized computation to analyze the DSS and DS repeated sequences' structure from the $\mathrm{C}$ terminus of DMP-2. The analysis showed that fully phosphorylated $\left(\mathrm{DS}^{*} \mathrm{~S}^{*}\right)_{n>3}$ has two adjacent $S^{\prime}$ phosphates in each triplet on opposite sides of the peptide chain and the D carboxyl groups are ar- ranged opposite the adjacent $S^{\prime}$ phosphate. Within the extended DSS arrangement, highly negatively charged SDS ridges are created. The DS arrangement is different from that of DSS because all the phosphates are on one side of the peptide chain and carboxyl on the other. Such SDS and DS arrangements will provide for $\mathrm{Ca}$ binding and mineral orientation. DMP-3 has a similar structure but shorter DSS repeated sequences [25]. It has been shown that DMP-2 and DMP-3 play an important role in dentinogensis [28]. Our SP2 has SDS and DS/KS/ ES structures, but there is no continuous carboxylphosphate ridge, which may affect the efficiency of HA nucleation. 
We have modeled the serine-rich motif of PP, SP2, as in $\beta$-sheet secondary structure using DeepView/ Swiss-Pdb Viewer v3.7 software (ExPASy, Basel, Switzerland). This model is very similar to previous models created by other authors but using different software $[25,26]$. The distance between the hydroxyl groups of every two adjacent serines is $6.6 \AA$. When the serine of SP2 is phosphorylated, phosphate replaces the hydrogen of the hydroxyl group but leaves oxygen unchanged. The distance between two phosphate groups of adjacent serines should not deviate from $6.6 \AA$ unless the repulsive force between the charged groups on the same side causes the trans extended chain to twist. This space is close to the HA crystalline unit cell dimensions (c = 6.85 $\AA$ ). As the hydroxyl groups of the serine are phosphorylated in PP, it is possible that this motif presented in the $\beta$-sheet secondary structure may attract $\mathrm{Ca}$ ions, acting as the template for HA crystal formation.

Analysis of the precipitate in our experiment by Xray diffraction (XRD) showed that $\mathrm{HA}$ was present but the $\mathrm{Ca} /$ phosphate ratio was between $1.58-1.62$. There could be several reasons why the "ideal" $\mathrm{Ca} /$ phosphate ratio of 1.67 was not obtained in the XRD analysis. First, the standard HA purchased from Sigma may have a lower $\mathrm{Ca} /$ phosphate ratio due to the acid phosphate which remained in the product during the manufacturing process. Second, amorphous phases may have been present in the precipitate, but none was categorically identified by XRD analysis. Third, surface inclusions and impurities would also affect the stoichiometric HA ratio of the precipitate. Finally, inclusion of $\mathrm{Ca}$ carbonate in the precipitate may be another reason for the lower $\mathrm{Ca} /$ phosphate ratio. There also appears to be Liesgang ring or band formation at the interface where Ca-phosphorus ions meet in the gel. These bands are due to the reaction kinetics and the diffusion of the chemical species in the gel. They are created by depletion of the nucleating ions, which causes the local supersaturation to drop in the neighborhood of the precipitation site and the ring or band to form. The amount and type of precipitation are obviously dependent on the molecules involved in nucleation, as discussed previously, as well as the incubation time, $\mathrm{pH}$, and ionic concentration at the precipitating interface. More work is needed to investigate these variables.

The mineral-nucleating system used in this experiment is similar to that designed by Hunter and Goldberg [42]. The $\mathrm{Ca} \times \mathrm{PO}_{4}$ product in our system was above the physiological range and Hunter and Goldberg's spontaneous precipitation threshold. The ions diffusing into the gel followed Fick's law, and the rate of diffusion was dependent on the cross section of the glass tube, the distance the ions had to diffuse, and the nature of the gels. These factors may not have been exactly the same in our system as the one used by Hunter and Goldberg; therefore, the efficiency of the ions diffusing into the gel may not be the same.

This study suggests that synthesized molecules, modeled on bioactive proteins, may be suitable for use in tissue regeneration and repair. Healy et al. [43-45] studied the effect of bone-derived cells growing on surfaces grafted with RGD-containing sequences of bone sialoprotein. Their work and ours demonstrate a great potential application for synthetic molecules in tissue engineering. Such molecules can be easily synthesized and do not have the immunological problems associated with nascent proteins and/or the quality/purification issues of recombinant molecules.

Acknowledgments. We thank Dr. Kai Sun and Dr. John F. Mansfield for their help with the TEM analysis. We also thank Dr. Qiming Jin for his help in improving the TEM image. This investigation was supported by NIH grant DE 12899.

\section{References}

1. Linde A (1989) Dentin matrix proteins: composition and possible functions in calcification. Anat Rec 224:154166

2. Veis A (1993) Mineral-matrix interactions in bone and dentin. J Bone Miner Res 8(suppl 2):S493-S497

3. Butler WT, Ritchie H (1995) The nature and functional significance of dentin extracellular matrix proteins. Int $\mathbf{J}$ Dev Biol 39:169-179

4. Butler WT, Bhown M, DiMuzio MT, Cothran WC, Linde A (1983) Multiple forms of rat dentin phosphoproteins. Arch Biochem Biophys 225:178-186

5. Takagi Y, Veis A (1984) Isolation of phosphophoryn from human dentin organic matrix. Calcif Tissue Int 36:259265

6. Chang SR, Chiego D Jr, Clarkson BH (1996) Characterization and identification of a human dentin phosphophoryn. Calcif Tissue Int 59:149-153

7. Nawrot CF, Campbell DJ, Schroeder JK, Van Valkenburg M (1976) Dental phosphoprotein-induced formation of hydroxylapatite during in vitro synthesis of amorphous calcium phosphate. Biochemistry 15:3445-3449

8. Zanetti M, de Bernard B, Jontell M, Linde A (1981) $\mathrm{Ca}^{2+}$ binding studies of the phosphoprotein from rat-incisor dentine. Eur J Biochem 113:541-545

9. Termine JD, Eanes ED, Conn KM (1980) Phosphoprotein modulation of apatite crystallization. Calcif Tissue Int 31:247-251

10. Lussi A, Crenshaw MA, Linde A (1988) Induction and inhibition of hydroxyapatite formation by rat dentine phosphoprotein in vitro. Arch Oral Biol 33:685-691

11. Linde A, Lussi A (1989) Mineral induction by polyanionic dentin and bone proteins at physiological ionic conditions. Connect Tissue Res 21:197-203

12. Boskey AL, Maresca M, Doty S, Sabsay B, Veis A (1990) Concentration-dependent effects of dentin phosphophoryn in the regulation of in vitro hydroxyapatite formation and growth. Bone Miner 11:55-65

13. Hunter GK, Hauschka PV, Poole AR, Rosenberg LC, Goldberg HA (1996) Nucleation and inhibition of hydroxyapatite formation by mineralized tissue proteins. Biochem J 317:59-64

14. D’Souza RN, Cavender A, Sunavala G, Alvarez J, Ohshima T, Kulkarni AB, MacDougall M (1997) Gene expression patterns of murine dentin matrix protein 1 (Dmp1) and dentin sialophosphoprotein (DSPP) suggest 
distinct developmental functions in vivo. J Bone Miner Res 12:2040-2049

15. George A, Sabsay B, Simonian PA, Veis A (1993) Characterization of a novel dentin matrix acidic phosphoprotein. Implications for induction of biomineralization. J Biol Chem 268:12624-12630

16. He G, Dahl T, Veis A, George A (2003) Dentin matrix protein 1 initiates hydroxyapatite formation in vitro. Connect Tissue Res 44(suppl 1):240-245

17. He G, Dahl T, Veis A, George A (2003) Nucleation of apatite crystals in vitro by self-assembled dentin matrix protein 1. Nat Mater 2:552-558

18. Tartaix PH, Doulaverakis M, George A, Fisher LW, Butler WT, Qin C, Salih E, Tan M, Fujimoto Y, Spevak L, Boskey AL (2004) In vitro effects of dentin matrix protein1 on hydroxyapatite formation provide insights into in vivo functions. J Biol Chem 279:18115-18120

19. van den Bos T, Steinfort J, Beertsen W (1993) Effect of bound phosphoproteins and other organic phosphates on alkaline phosphatase-induced mineralization of collagenous matrices in vitro. Bone Miner 23:81-93

20. Narayanan K, Ramachandran A, Hao J, He G, Park KW, Cho M, George A (2003) Dual functional roles of dentin matrix protein 1 Implications in biomineralization and gene transcription by activation of intracellular $\mathrm{Ca} 2+$ store. J Biol Chem 278:17500-17508

21. Wallwork ML, Kirkham J, Chen H, Chang SX, Robinson C, Smith DA, Clarkson BH (2002) Binding of dentin noncollagenous matrix proteins to biological mineral crystals: an atomic force microscopy study. Calcif Tissue Int 71:249-255

22. Wu CB, Pelech SL, Veis A (1992) The in vitro phosphorylation of the native rat incisor dentin phosphophoryns. J Biol Chem 267:16588-16594

23. Zeichner-David M, Hall F, Williams R, Thiemann F, Yen S, MacDougall M, Slavkin HC (1995) Characterization of protein kinases involved in dentinogenesis. Connect Tissue Res 33:87-95

24. Ritchie HH, Wang LH (1996) Sequence determination of an extremely acidic rat dentin phosphoprotein. J Biol Chem 271:21695-21698

25. Veis A, Wei K, Sfeir C, George A, Malone J (1998) Properties of the (DSS) $n$ triplet repeat domain of rat dentin phosphophoryn. Eur J Oral Sci 106(suppl 1):234-238

26. George A, Bannon L, Sabsay B, Dillon JW, Malone J, Veis A, Jenkins NA, Gilbert DJ, Copeland NG (1996) The carboxyl-terminal domain of phosphophoryn contains unique extended triplet amino acid repeat sequences forming ordered carboxyl-phosphate interaction ridges that may be essential in the biomineralization process. $\mathbf{J}$ Biol Chem 271:32869-32873

27. George A, Srinivasan R, Thotakura S, Veis A (1998) The phosphophoryn gene family: identical domain structures at the carboxyl end. Eur J Oral Sci 106(suppl 1):221-226

28. Thotakura SR, Mah T, Srinivasan R, Takagi Y, Veis A, George A (2000) The non-collagenous dentin matrix proteins are involved in dentinogenesis imperfecta type II (DGI-II). J Dent Res 79:835-839

29. MacDougall M, Simmons D, Luan X, Nydegger J, Feng J, Gu TT (1997) Dentin phosphoprotein and dentin sialoprotein are cleavage products expressed from a single transcript coded by a gene on human chromosome 4 . Dentin phosphoprotein DNA sequence determination. J Biol Chem 272:835-842
30. Ritchie H, Wang LH (1997) A mammalian bicistronic transcript encoding two dentin-specific proteins. Biochem Biophys Res Commun 231:425-428

31. Gu K, Chang S, Ritchie HH, Clarkson BH, Rutherford RB (2000) Molecular cloning of a human dentin sialophosphoprotein gene. Eur J Oral Sci 108:35-42

32. Ritchie HH, Berry JE, Somerman MJ, Hanks CT, Bronckers AL, Hotton D, Papagerakis P, Berdal A, Butler WT (1997) Dentin sialoprotein (DSP) transcripts: developmentally-sustained expression in odontoblasts and transient expression in pre-ameloblasts. Eur J Oral Sci 105:405-413

33. Butler WT, Bhown M, Brunn JC, D'Souza RN, FarachCarson MC, Happonen RP, Schrohenloher RE, Seyer JM, Somerman MJ, Foster RA (1992) Isolation, characterization and immunolocalization of a 53-kDa dentin sialoprotein (DSP). Matrix 12:343-351

34. D’Souza RN, Bronckers AL, Happonen RP, Doga DA, Farach-Carson MC, Butler WT (1992) Developmental expression of a $53 \mathrm{kD}$ dentin sialoprotein in rat tooth organs. J Histochem Cytochem 40:359-366

35. Bronckers AL, Farach-Carson MC, Van Waveren E, Butler WT (1994) Immunolocalization of osteopontin, osteocalcin, and dentin sialoprotein during dental root formation and early cementogenesis in the rat. $\mathrm{J}$ Bone Miner Res 9:833-841

36. Boskey A, Spevak L, Tan M, Doty SB, Butler WT (2000) Dentin sialoprotein (DSP) has limited effects on in vitro apatite formation and growth. Calcif Tissue Int 67:472-478

37. Butler WT, Bhown M, DiMuzio MT, Linde A (1981) Non-collagenous proteins of dentin Isolation and partial characterization of rat dentin proteins and proteoglycans using a three-step preparative method. Collagen Relat Res 1:187-199

38. Chen PS, Toribara TY, Warner H (1956) Microdetermination of phosphorus. Anal Chem. 28:1756-1758

39. Leventouri T, Bunaciu CE, Perdikatsis V (2003) Neutron powder diffraction studies of silicon-substituted hydroxyapatite. Biomaterials 24:4205-4211

40. Fujisawa R, Wada Y, Nodasaka Y, Kuboki Y (1996) Acidic amino acid-rich sequences as binding sites of osteonectin to hydroxyapatite crystals. Biochim Biophys Acta 1292:53-60

41. Tye CE, Rattray KR, Warner KJ, Gordon JA, Sodek J, Hunter GK, Goldberg HA (2003) Delineation of the hydroxyapatite-nucleating domains of bone sialoprotein. J Biol Chem 278:7949-7955

42. Hunter GK, Goldberg HA (1993) Nucleation of hydroxyapatite by bone sialoprotein. Proc Natl Acad Sci USA 90:8562-8565

43. Rezania A, Thomas $\mathrm{CH}$, Branger AB, Waters CM, Healy KE (1997) The detachment strength and morphology of bone cells contacting materials modified with a peptide sequence found within bone sialoprotein. J Biomed Mater Res 37:9-19

44. Bearinger JP, Castner DG, Healy KE (1998) Biomolecular modification of $\mathrm{p}$ (AAm-co-EG/AA) IPNs supports osteoblast adhesion and phenotypic expression. J Biomater Sci Polym Ed 9:629-652

45. Barber TA, Golledge SL, Castner DG, Healy KE (2003) Peptide-modified p(AAm-co-EG/AAc) IPNs grafted to bulk titanium modulate osteoblast behavior in vitro. J Biomed Mater Res 64A:38-47 